\title{
The influence of perceived control and self-efficacy on the sensory evaluation of experimentally induced pain
}

Citation for published version (APA):

Vancleef, L. M. G., \& Peters, M. L. (2011). The influence of perceived control and self-efficacy on the sensory evaluation of experimentally induced pain. Journal of Behavior Therapy and Experimental Psychiatry, 42(4), 511-517. https://doi.org/10.1016/j.jbtep.2011.05.006

Document status and date:

Published: 01/12/2011

DOI:

10.1016/j.jbtep.2011.05.006

Document Version:

Publisher's PDF, also known as Version of record

Document license:

Taverne

Please check the document version of this publication:

- A submitted manuscript is the version of the article upon submission and before peer-review. There can be important differences between the submitted version and the official published version of record.

People interested in the research are advised to contact the author for the final version of the publication, or visit the DOI to the publisher's website.

- The final author version and the galley proof are versions of the publication after peer review.

- The final published version features the final layout of the paper including the volume, issue and page numbers.

Link to publication

\footnotetext{
General rights rights.

- You may freely distribute the URL identifying the publication in the public portal. please follow below link for the End User Agreement:

www.umlib.nl/taverne-license

Take down policy

If you believe that this document breaches copyright please contact us at:

repository@maastrichtuniversity.nl

providing details and we will investigate your claim.
}

Copyright and moral rights for the publications made accessible in the public portal are retained by the authors and/or other copyright owners and it is a condition of accessing publications that users recognise and abide by the legal requirements associated with these

- Users may download and print one copy of any publication from the public portal for the purpose of private study or research.

- You may not further distribute the material or use it for any profit-making activity or commercial gain

If the publication is distributed under the terms of Article $25 \mathrm{fa}$ of the Dutch Copyright Act, indicated by the "Taverne" license above, 


\title{
The influence of perceived control and self-efficacy on the sensory evaluation of experimentally induced pain
}

\author{
Linda M.G. Vancleef*, Madelon L. Peters \\ Department Clinical Psychological Science, Maastricht University, P.O. Box 616, 6200 MD Maastricht, The Netherlands
}

\section{A R T I C L E I N F O}

\section{Article history:}

Received 18 June 2010

Received in revised form

19 May 2011

Accepted 30 May 2011

Keywords:

Self-efficacy

Sensory pain

Pain resilience

\begin{abstract}
A B S T R A C T
Background and aims: Prior research has demonstrated the role of perceived control and self-efficacy beliefs over pain in reducing pain and pain-related disability. The present study aimed to examine the independent influence of perceived control and self-efficacy beliefs on the subjective evaluation of pain. Methods: Healthy participants $(N=79)$ were randomly assigned to one of four conditions that were formed by manipulations of perceived control and self-efficacy. At two occasions in the experimental procedure pain was induced by means of electrical stimulation (16s) to the lower forearm. Prior to and following upon each pain stimulus, participants completed ratings of pain intensity and pain unpleasantness.

Results: High self-efficacy regarding the ability to exert control over pain resulted in a significant reduction in anticipated pain intensity, anticipated pain unpleasantness, and experienced pain intensity ratings. Furthermore, anticipated pain intensity was found to mediate the relation between self-efficacy and experienced pain intensity.

Conclusions: It is concluded that in order to observe beneficial effects of offering control over pain, it is important that individuals are convinced (i.e. have high self-efficacy) that they are able to exert this control successfully.
\end{abstract}

(c) 2011 Elsevier Ltd. All rights reserved.

\section{Introduction}

Although a substantial body of research is available on potential vulnerability and risk factors for chronic pain, research into factors and mechanisms that influence the course of pain beneficially is still sparse.

One cognitive construct that has been proposed as a mediator of decreased pain and disability is perceived control, or the belief that one has at one's disposal a response that can influence the aversiveness of an event (Thompson, 1981). In (chronic) pain patients, perceived control has been found associated with improved patient functioning, increased activity levels, treatment satisfaction, and lower perceived pain severity (Jensen \& Karoly, 1991; Pellino \& Ward, 1998; Tan, Jensen, Robinson-Whelen, Thornby, \& Monga, 2002). In healthy volunteers, perceived control over pain has been found related to increased tolerance and prolonged endurance of experimentally induced pain (Arntz \& Schmidt, 1989; Feldner \& Hekmat, 2001). Janssen, Spinhoven, and Arntz (2004) demonstrated that successful control over pain has a positive influence on individuals' mood. It is important to note that the mere idea of being able to

\footnotetext{
* Corresponding author. Tel.: +31 43 3882485; fax: +31 433884155.

E-mail addresses: L.Vancleef@maastrichtuniversity.nl (L.M.G. Vancleef) madelon.peters@maastrichtuniversity.nl (M.L. Peters).
}

control pain suffices to obtain these beneficial effects, irrespective of whether this control is genuinely effective or utilized (Arntz \& Schmidt, 1989). Nevertheless, effects of perceived control over pain appear to be restricted to behavioral and emotional responses to pain (pain tolerance, pain endurance, happiness). Arntz and Schmidt (1989) suggested that perceived control over pain particularly alters the perceived threat value and thus the meaning of the pain, leading to observable benefits in objective responses to pain that do not extend to its subjective sensory experience. Supporting this suggestion, perceived control over anxiety-related events (interpreted as control over threatening, anxiety inducing situations) appeared to be associated with longer tolerance and endurance of cold-pressor pain, but not with decreases in subjective pain intensity, heart rate, or pain threshold (Feldner \& Hekmat, 2001).

A second cognitive factor that is assumed to mediate pain and disability is self-efficacy (SE), or the belief one has in the ability to organize and perform the behaviors that are necessary to achieve desired goals (Bandura, 1977). Research in the domain of pain predominantly focussed on specific SE, which is defined as the belief one has in one's own capability to achieve desired outcomes using a specific task, strategy, or technique to reduce pain or cope with a certain pain stimulus (Litt, 1988; Rokke, Fleming Ficek, Siemens, \& Hegstad, 2004). Specific SE was found to mediate the relation between pain intensity and disability, and to be predictive of pain 
tolerance and pain endurance (Arnstein, 2000; Baker \& Kirsch, 1991; Denison, Asenlof, \& Lindberg, 2004; Litt, 1988; Rokke et al., 2004; Williams \& Kinney, 1991). Congruently with findings on perceived control, the beneficial effects of SE appear to be predominantly restricted to behavioral pain responses, although effects of SE on reported pain intensity have been observed occasionally (e.g. Jackson, Iezzi, Gunderson, Nagasaka, \& Fritch, 2002; Rokke et al., 2004).

Even though most of the research on the influence of perceived control and SE on pain has focussed on studying one of both constructs, it well acknowledged that both constructs are intrinsically related to each other (Litt, 1988; Pellino \& Ward, 1998; Rokke et al., 2004). Litt (1988) demonstrated that the benefits of perceived control over pain on pain tolerance were the greatest for those who were most confident (i.e. high self-efficacious) that they were able to exercise this control. In a similar vein, Jensen and Karoly (1991) emphasized that in order to achieve improved well-being and activity levels in pain patients, the belief in ones personal ability to control pain is as important as the belief in the control strategy itself.

In sum, prior studies have clearly demonstrated the importance of both perceived control and SE beliefs in the perception and experience of pain. These studies demonstrated beneficial effects of both constructs to be largely restricted to behavioral and emotional responses to pain (tolerance, endurance, happiness), not extending to the subjective evaluation of pain. In addition, with exception of the study by Litt (1988), prior studies have focused on examining effects of either perceived control or specific SE beliefs in the context of pain, thereby not exploring their interaction on pain outcome measures. Given the fact that most studies on effects of SE on the perception of pain have operationalized SE as the belief in one's ability to manage pain by the use of a specific strategy or technique, it might be proposed that these studies actually examined the influence of SE beliefs regarding a perceived control possibility on the pain experience (e.g. Arnstein, 2000; Jackson et al., 2002; Rokke et al., 2004).However, because these studies make no distinction between perceived control and SE beliefs regarding this control, it is impossible to decide whether findings of these studies are mainly attributable to the effect of SE beliefs, the effect of perceived control beliefs, or their interaction.

The current study was specifically set up to examine the (independent) influence of perceived control and specific SE on the subjective sensory evaluation of pain. It is hypothesized that: (i) perceived control over pain is associated with lower anticipatory and experienced subjective pain ratings, and (ii) the effects of perceived control are especially pronounced in participants possessing high SE regarding this control. Furthermore, because SE is assumed to be relevant for individuals who believe in the controllability of pain, effects of SE are hypothesized to occur in those who have perceived control over pain only.

\section{Methods}

\subsection{Participants}

Participants ( $N=80$; 59 female; $M_{\text {age }}=24.49$ years, $s d=6.78$, range $=18-49$ ) were recruited at Maastricht's university local community. Because pain was induced by administering electrical stimulation on the forearm, wearing a pacemaker, suffering from cardiovascular disorders, thrombosis, or recent injury at the nondominant forearm formed exclusion criteria. Present pain complaints (i.e. headache, menstrual pain, stomach pain, etc.) at the moment of testing formed an additional exclusion criterion because the presence of pain at the moment of testing might impact results in an undesirable way (e.g. interfering with pain intensity ratings.) Compliance with inclusion criteria was verbally checked when a test appointment was scheduled, and was once again queried when the participant arrived at the test appointment. All participants gave informed consent and received financial compensation for participating. Prior to the start of the experiment, participants were randomly assigned to a perceived control condition $(N=41,28$ female) or a neutral condition ( $N=39,31$ female). Both conditions received differential instructions as to the goal of the experiment. Within the perceived control and the neutral condition, participants were randomly assigned to a high SE group and a low SE group. This way, four groups were created: (1) perceived control-low SE $(n=21$, $M_{\mathrm{age}}=24.14, s d=6.76,15$ female); (2) perceived control-high SE $\left(n=20, M_{\text {age }}=26.45, s d=8.67,13\right.$ female $)$; (3) neutral-low SE $(n=19$, $M_{\mathrm{age}}=23.63, s d=6.68,18$ female); and (4) neutral-high SE group ( $n=19, M_{\mathrm{age}}=23.74, s d=4.63,13$ female). One participant was excluded from data analyses, because for this person, pain tolerance was not reached within the preset boundaries of electrical stimulation intensity (between .4 and $10.0 \mathrm{~mA}$ ). As such, data analyses were conducted on 79 participants ( 59 female, $M_{\mathrm{age}}=24.51$, $s d=6.83$, range $=18-49$ ). The Ethics Committee of the University Hospital Maastricht/Maastricht University approved the research protocol.

\subsection{Materials and measures}

\subsubsection{Electrical stimulation}

The electrical stimulation was delivered through one pair of $\mathrm{Ag} / \mathrm{AgCl}$ electrodes (diameter $=8 \mathrm{~mm}$; interelectrode distance $10 \mathrm{~mm}$ ), filled with hypertonic gel (spectra EEG gel) that were attached to the ventral forearm of the non-dominant arm. The skin area beneath the electrodes was first rubbed with peeling gel to reduce skin resistance. The stimulation consisted of rectangular pulses at a rate of $2 \mathrm{~Hz}$, produced by a constant current stimulator (IDEE, Maastricht University). The electrical stimuli had a duration of $3 \mathrm{~s}$ in the calibration phase and of $16 \mathrm{~s}$ in the experimental phase (see procedure section). The intensity of the electrical stimulation was individually established with a maximum intensity of $10 \mathrm{~mA}$ (see procedure section).

\subsubsection{Anticipatory and experience variables}

Visual Analogue Scales (VAS, $100 \mathrm{~mm}$ ) were administered to assess anticipated and experienced pain intensity ('How much pain do you expect the next electrical stimulus to cause'; 'How much pain did you experience with the electrical stimulus'), and pain unpleasantness ('How unpleasant do you think the next electrical stimulus will be'; 'How unpleasant did you find the electrical stimulus'). These VASs were anchored with 'no pain/not at all unpleasant' at one end and 'very much pain/very unpleasant' at the other end.

\subsubsection{Manipulation check}

The effectiveness of the manipulation of both perceived control and SE was checked immediately after practicing with the biofeedback strategy and the induction of the SE beliefs. At this stage, participants were both acquainted with the strategy, and had received instructions regarding their ability to use the strategy successful (see Procedure). The effect of the perceived control manipulation was checked with the following question: "To what extent do you believe that performing this biofeedback strategy will have an influence on the pain stimulus?" The effect of the manipulation of SE was queried as follows: "How good do you think that you are in practicing the biofeedback strategy in comparison to others?" Both questions were answered on a 100 mm VAS anchored with "not at all" and "very much".

\subsection{Procedure}

For an overview of the experimental procedure see the flowchart in Fig. 1. Participants were tested individually in a sound- 


\begin{tabular}{|c|c|c|c|c|c|c|c|c|c|c|}
\hline $\begin{array}{l}\text { Assignment to } \\
\text { perceived control } \\
\text { or neutral group: } \\
\text { written \& verbal } \\
\text { instruction }\end{array}$ & $\begin{array}{l}\text { Calibration } \\
\text { phase for } \\
\text { pain } \\
\text { induction }\end{array}$ & $\begin{array}{l}\text { Anticipatory pain } \\
\text { intensity \& pain } \\
\text { unpleasantness } \\
\text { rating (VAS) }\end{array}$ & $\begin{array}{l}\text { Pain } \\
\text { induction } \\
(16 \mathrm{~s})\end{array}$ & $\begin{array}{l}\text { Experience pain } \\
\text { intensity and pain } \\
\text { unpleasantness } \\
\text { rating (VAS) }\end{array}$ & $\begin{array}{l}\text { Practice } \\
\text { biofeedback } \\
\text { strategy }\end{array}$ & $\begin{array}{l}\text { Manipulation } \\
\text { task-specific } \\
\text { self efficacy }\end{array}$ & $\begin{array}{l}\text { Manipulation } \\
\text { check } \\
\text { (VAS) }\end{array}$ & $\begin{array}{l}\text { Anticipatory pain } \\
\text { intensity \& pain } \\
\text { unpleasantness } \\
\text { rating (VAS) }\end{array}$ & $\begin{array}{l}\text { Pain induction } \\
\text { (16s) while } \\
\text { performing } \\
\text { biofeedback } \\
\text { strategy }\end{array}$ & $\begin{array}{l}\text { Experience pain } \\
\text { intensity \& pain } \\
\text { unpleasantness } \\
\text { rating (VAS) }\end{array}$ \\
\hline
\end{tabular}

Fig. 1. Flowchart for the experimental procedure.

attenuated room in the university building, specifically designed for experimental procedures and the use of the electrical stimulator. The experimental procedure was identical for all participants. Deception was used to manipulate participants' perceived control and SE beliefs.

\subsubsection{Assignment to perceived control or neutral condition}

Upon arrival to the laboratory, participants in the perceived control condition were instructed that they took part in a study that aimed to examine the beneficial influence of performing a biofeedback strategy on the pain experience. Participants in the neutral condition were instructed that they took part in a study that aimed to examine how the administration of a pain stimulus might influence the efficacy of performing a biofeedback strategy. These instructions were provided in two ways. First, participants read these in the participant information letter that accompanied the informed consent form, and which was mandatory to read prior to giving informed consent. Second, the experimenter explained the goal of the study verbally, thereby stressing the aim of the biofeedback strategy in both conditions. The electrodes for the electrical stimulation were attached and the calibration phase was started.

\subsubsection{Calibration phase and baseline pain stimulus}

The individual intensity level of the electrical stimulus was determined on the basis of the individual tolerance level for this specific pain stimulus (Janssen et al., 2004; Peters, Vlaeyen, \& Kunnen, 2002; Roelofs, Peters, Deutz, Spijker, \& Vlaeyen, 2005). The calibration phase consisted of a series of electrical stimuli (duration $=3 \mathrm{~s}$ ) of gradual increasing intensity, with a start intensity of $.4 \mathrm{~mA}$ and a stepwise increase of $4 \mathrm{~mA}$. Participants had to indicate pain threshold (the lowest intensity level that is rated as painful) and pain tolerance (the highest intensity level that is rated as tolerable). The participant could communicate with the experimenter through an intercom that connected the test room with the adjacent experimenter room. The experimenter started each electrical stimulus manually and could stop the presentation of the stimulus instantly if necessary. In addition, participants had an emergency button at their disposal, which could be pushed to break off the electrical stimulation instantaneously in case of extreme distress. The procedure was ended when the participant indicated that pain tolerance was reached, and was repeated four times with 1 min intervals in between them. Taking into account possible sensitization effects, we disregarded the first series of electrical stimuli, and the highest tolerance level out of the last three series was chosen as the intensity that would be administered as the experimental stimulus. Before the experiment continued, however, it was tested whether this intensity level could be tolerated for $16 \mathrm{~s}$, corresponding to the duration of the electrical stimulus that would be adopted in the experimental phase. If the stimulus could not be tolerated for $16 \mathrm{~s}$, the calibration procedure foresaw the possibility to decrease the intensity in steps of $.4 \mathrm{~mA}$ until the stimulus was tolerable for $16 \mathrm{~s}$. However, in the current study, it was not necessary to adapt the pain intensity for any of the participants this way.
After the calibration phase, a 2-min break was introduced. Participants received instructions about how to understand the VAS questions, and were informed that the first VAS question asked about painfulness in terms of pain intensity, whereas the second VAS question asked about the unpleasantness of the pain experience. Participants then rated anticipated pain intensity and pain unpleasantness. The first experimental stimulus was then administered for $16 \mathrm{~s}$, and ratings of experienced pain intensity and pain unpleasantness were provided.

\subsubsection{Concretization biofeedback strategy and strengthening the perceived control manipulation}

All participants received instructions about how to perform the (fictive) biofeedback strategy. This strategy consisted of making a squeeze movement with the dominant hand (open and close at a regular pace) for a total duration of 2 min while the arm rested stretched out on the table. Participants were instructed to concentrate and focus attention to this movement while performing it.

To strengthen the manipulation of perceived control that was made in the introductionary instructions prior to the experiment, further instructions regarding the rationale and objective of this strategy differed for participants in the perceived control and the neutral group.

Participants in the perceived control group were led to believe that the biofeedback strategy enabled them to control their pain experience in a positive way. They were told that lower pain is experienced in areas with low skin conductance, and that the squeezing activity leads to reduction in skin conductance in inactive areas (non-dominant arm side, i.e. site of ES administration). They were furthermore told that it has been scientifically proven that diverting attention away from the pain site to something else can lead to a significant reduction of pain, because relaxation and concentration on things other than pain lead to lowered skin conductance.

Participants in the neutral group were told that scientific medical research has demonstrated that individuals are capable of reducing their own skin conductance, for example through the use of biofeedback procedures. They were told that it is yet unclear however, whether such strategies are still effective in reducing skin conductance level when a pain stimulus is administered during performance of the strategy.

After these instructions, participants in both groups practiced the biofeedback procedure, while the skin conductance was fictively measured and a skin conductance curve ran synchronously on the computer screen in front of the participants.

\subsubsection{Self-efficacy manipulation}

While practicing the squeeze movement for $2 \mathrm{~min}$, skin conductance was (fictively) measured through two $9 \mathrm{~mm} \mathrm{Ag}-\mathrm{AgCl}$ electrodes that were attached to the middle phalanx of the index and third finger of the non-dominant hand. While participants practiced with the biofeedback strategy, a skin conductance curve ran synchronously on a computer screen in front of them. Participants were led to belief that they monitored their own skin 
conductance pattern on screen. All participants were presented with the same skin conductance pattern on the computer screen, which was created by adding a constant decreasing factor to a genuine skin conductance pattern. This resulted in a visual decrease of the skin conductance curve for all participants. After 2 min, a pre-programmed number was shown in the bottom right corner of the computer screen that reflected the mean (fictive) decrease in skin conductance. This number was generated by the computer and was programmed in such a way that this number could either have a high value ( $30 \pm 10 \%)$ or a low value (10 $\pm 10 \%)$, reflecting high or low decrease in skin conductance. After performing the biofeedback squeeze movement for $2 \mathrm{~min}$, the experimenter indicated that participants could stop the squeezing movement and the mean decrease in skin conductance was shown in the bottom right corner of the computer screen. SE beliefs were then induced by comparing this number to a (fictive) norm table that was shown to participants. We designed two norm tables for the purpose of the SE manipulation (i.e. for the high and low SE manipulation respectively), in which fictive mean decrease rates in skin conductance level were presented for several age cohorts, and for males and females separately. Several studies have shown that comparing performance of persons with that of their peers is an effective way to manipulate self-efficacy expectations (Litt, 1988). Participants in the high SE group were told and shown that they were very good in comparison to their peers in reducing their skin conductance. Participants in the low SE group were told and shown that they were rather bad in reducing their skin conductance in comparison to their peers. To increase credibility of the manipulation, participants were instructed to practice the biofeedback strategy once again to verify whether the first outcome was not biased because it only constituted the first practice with the strategy. The number that reflected the decrease in skin conductance was programmed to result in a comparable, but not identical value as before, and enabled the experimenter to stress whether someone was really good (high SE) or really bad (low SE) in reducing skin conductance. Next, participants completed the manipulation check questions.

\subsubsection{Experimental electrical stimulus}

Before administration of the second electrical stimulus participants rated anticipated pain intensity and pain unpleasantness. They were then instructed to initiate the biofeedback strategy. Ten seconds later, the experimental pain stimulus was started. Participants continued their performance of the biofeedback strategy until the electrical stimulus ended (after $16 \mathrm{~s}$ ). This time, the skin conductance curve was not shown to participants. Participants rated the experienced pain and pain unpleasantness immediately upon the ending of the electrical stimulus. When data collection was completed, all participants received a debriefing letter, explaining the exact research aims.

\subsection{Statistical analysis}

The effectiveness of the manipulations of perceived control and SE was tested with a $2 \times 2$ ANOVA with Perceived Control (control vs neutral) and SE (high vs. low) as between subject factors, and the manipulation check questions as dependent variables.

The effects of Perceived Control and SE on the sensory pain ratings (anticipatory and experienced) were analyzed with $2 \times 2$ ANCOVA's with SE (high vs. low) and Perceived Control (control vs. neutral) as between-subjects factors. Sex and ratings provided with the first experimental pain stimulus (rating 1) were entered as covariates in these analyses. Significant interaction effects were further examined with additional one-way ANCOVA's.
Table 1

Means (sd) for the perceived control and self-efficacy manipulation check questions.

\begin{tabular}{|c|c|c|c|c|c|c|c|}
\hline & & \multicolumn{2}{|c|}{ Neutral group } & \multicolumn{2}{|c|}{$\begin{array}{l}\text { Perceived } \\
\text { control group }\end{array}$} & \multicolumn{2}{|l|}{ Total } \\
\hline & & $M$ & $(s d)$ & $M$ & $(s d)$ & $M$ & $(s d)$ \\
\hline \multirow{3}{*}{$\begin{array}{l}\text { Perceived control } \\
\text { manipulation }\end{array}$} & Low SE & 35.42 & $(19.22)$ & 33.76 & $(17.15)$ & 34.55 & $(17.94)$ \\
\hline & High SE & 55.89 & (13.03) & 61.80 & $(16.09)$ & 58.92 & (17.79) \\
\hline & Total & 45.66 & (19.23) & 47.79 & (21.71) & 46.58 & (20.44) \\
\hline \multirow{3}{*}{$\begin{array}{l}\text { Self-efficacy } \\
\text { manipulation }\end{array}$} & Low SE & 21.10 & (12.50) & 24.86 & (16.67) & 23.08 & (14.78) \\
\hline & High SE & 67.78 & (15.07) & 72.95 & $(14.11)$ & 70.43 & (14.62) \\
\hline & Total & 44.45 & $(27.31)$ & 48.32 & $(28.74)$ & 46.45 & (27.95) \\
\hline
\end{tabular}

Note. $\mathrm{SE}=$ self-efficacy

\section{Results}

\subsection{Pain threshold, pain tolerance, and effectiveness of the manipulations}

Mean pain threshold level in the study was $2.75 \mathrm{~mA}(s d=1.15)$, and mean pain tolerance level was $4.30 \mathrm{~mA}(s d=1.70)$. The perceived control condition and the neutral condition did not differ in pain threshold $\left(M_{\text {perceived control group }}=2.80 \mathrm{~mA} ; M_{\text {neutral }}\right.$ group $=2.68 \mathrm{~mA})$ and pain tolerance $\left(M_{\text {perceived control group }}=4.54 \mathrm{~mA}\right.$; $M_{\text {neutral group }}=4.04 \mathrm{~mA}$ ) scores.

Table 1 depicts the mean scores on the manipulation check questions. The $2 \times 2$ ANOVA on the manipulation check questions resulted in a main effect of SE on both manipulation check questions. Supporting the effectiveness of the SE manipulation, participants in the high SE group believed that they were better in reducing their skin conductance with the biofeedback strategy than participants in the low SE condition $(F(1,75)=102.14, p<.001$, $\left.\eta_{p}{ }^{2}=.73\right)$. Furthermore, the high SE group also believed more firmly that the biofeedback strategy would influence the pain stimulus compared than people in the low SE group $(F(1,75)=42.43, p<.001$ $\left.\eta_{p}{ }^{2}=.36\right)$. No main effect of perceived control, or an interaction effect between perceived control and SE was observed for either the SE manipulation check or the perceived control manipulation check $\left(p>.05, \eta_{p}^{2} \leq .03\right)$.

\subsection{Effects of perceived control and specific SE on anticipatory pain ratings}

Descriptive statistics of the anticipatory pain ratings in the four experimental groups are presented in Table 2.

Table 2

Means (sd) for anticipatory pain intensity and pain unpleasantness ratings $(N=79)$.

\begin{tabular}{|c|c|c|c|c|c|c|c|}
\hline & & \multicolumn{2}{|c|}{ Neutral group } & \multicolumn{2}{|c|}{$\begin{array}{l}\text { Perceived } \\
\text { control group }\end{array}$} & \multicolumn{2}{|l|}{ Total } \\
\hline & & $M$ & $(s d)$ & $M$ & $(s d)$ & $M$ & $(s d)$ \\
\hline \multirow[t]{3}{*}{ Intensity ES 1} & Low SE & 57.47 & $(20.24)$ & 61.43 & (11.15) & 59.55 & (16.03) \\
\hline & High SE & 60.26 & (16.33) & 55.25 & (21.33) & 57.69 & (18.98) \\
\hline & Total & 58.86 & (18.19) & 58.41 & (16.97) & 58.63 & (17.46) \\
\hline \multirow[t]{3}{*}{ Intensity ES 2} & Low SE & 52.26 & (19.36) & 56.52 & (15.48) & 54.50 & (17.34) \\
\hline & High SE & 49.37 & (19.69) & 38.80 & (25.62) & 43.95 & (23.25) \\
\hline & Total & 50.81 & (19.31) & 47.87 & (22.63) & 49.29 & $(21.02)$ \\
\hline Unpleasantness & Low SE & 66.74 & (21.27) & 67.14 & (11.49) & 66.95 & (16.63) \\
\hline \multirow[t]{2}{*}{ ES 1} & High SE & 63.37 & (22.62) & 65.05 & (22.79) & 64.23 & $(22.42)$ \\
\hline & Total & 65.05 & (21.72) & 66.12 & (17.71) & 65.61 & (19.62) \\
\hline Unpleasantness & Low SE & 58.37 & (21.58) & 63.05 & (15.81) & 60.83 & (18.67) \\
\hline \multirow[t]{2}{*}{ ES 2} & High SE & 60.68 & (24.91) & 50.85 & (28.79) & 55.64 & $(27.08)$ \\
\hline & Total & 59.53 & (23.02) & 57.09 & (23.59) & 58.27 & $(23.20)$ \\
\hline
\end{tabular}

Note. ES 1 = first $16 \mathrm{~s}$ electrical pain stimulus; ES 2 = second $16 \mathrm{~s}$ electrical pain stimulus; $\mathrm{SE}=$ self-efficacy. 


\subsubsection{Anticipatory pain intensity ratings}

The ANCOVA resulted in a significant effect of the covariate rating 1 (i.e. the anticipatory intensity rating for the first experimental pain stimulus), $F(1,73)=63.63, p<.001, \eta_{p}{ }^{2}=.47$. The effect of the other covariate, gender, was insignificant $(p>.05$, $\left.\eta_{p}{ }^{2}=.001\right)$. Furthermore, the effect of SE was found to be significant $\left(F(1,73)=7.13, p<.01, \eta_{p}{ }^{2}=.09\right)$. Participants in the high SE group (adjusted $M=44.78$ ) rated the second pain stimulus significantly lower than participants in the low SE group (adjusted $M=53.75$ ). The effects of perceived control $\left(p>.05, \eta_{p}{ }^{2}=.01\right)$ or perceived control $\times$ SE were insignificant $\left(p>.05, \eta_{p}{ }^{2}=.02\right)$.

\subsubsection{Anticipatory pain unpleasantness ratings}

The ANCOVA resulted in a significant effect for the covariate rating $1,\left(F(1,73)=68.13, p<.001, \eta_{p}^{2}=.48\right)$. The effect of the other covariate, gender, was insignificant $\left(p>.05, \eta_{p}{ }^{2}=.04\right)$. Furthermore, the perceived control $\times$ SE effect was significant with $F(1,73)=5.13$, $p=.03, \eta_{p}{ }^{2}=.07$. No other main effects were observed $(p>.05$, $\left.\eta_{p}{ }^{2}<.01\right)$. Fig. 2 displays the mean scores for this interaction, and illustrates that the perceived control-high SE condition show the lowest expected pain unpleasantness scores. The interaction effect was further examined with ANCOVA's, conducted within each condition separately with SE as between-subjects factor. Within the perceived control group, persons with high SE beliefs (adjusted $M=51.63$ ) on the biofeedback strategy anticipated lower pain intensity than persons with low SE on the biofeedback strategy (adjusted $M=62.31$ ) with $F(1,37)=2.84, p=.10, \eta_{p}^{2}=.07$. Within the neutral group, the anticipatory pain intensity for the high SE group (adjusted $M=62.11$ ) was not substantially different from the low SE group (adjusted $M=56.94$ ), with $F(1,34)=.86, p=.36, \eta_{p}^{2}=.03$.

\subsection{Effects of perceived control and specific SE on experienced pain ratings}

Table 3 depicts descriptive statistics of the experienced pain ratings in the four experimental groups.

\subsubsection{Experienced pain intensity ratings}

The ANCOVA resulted in a significant effect of the covariate rating $1, F(1,73)=119.91, p<.001, \eta_{p}{ }^{2}=.62$. The effect of the other

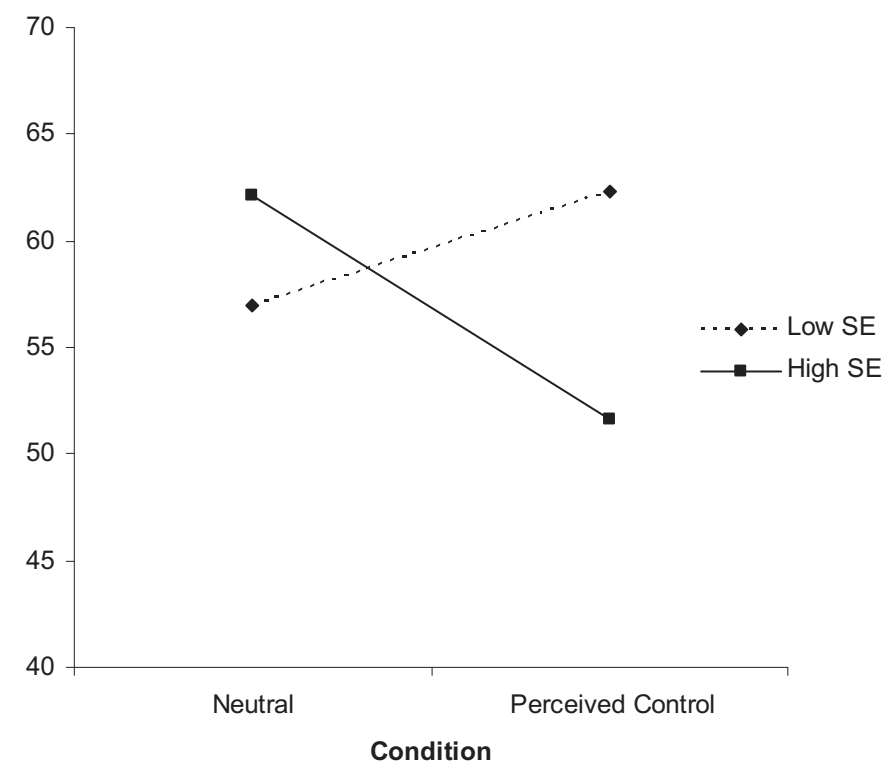

Fig. 2. Interaction effect (adjusted means) for anticipatory pain unpleasantness.
Table 3

Means (sd) for experienced pain intensity and pain unpleasantness ratings $(N=79)$.

\begin{tabular}{|c|c|c|c|c|c|c|c|}
\hline & & \multicolumn{2}{|c|}{ Neutral group } & \multicolumn{2}{|c|}{$\begin{array}{l}\text { Perceived } \\
\text { control group }\end{array}$} & \multicolumn{2}{|l|}{ Total } \\
\hline & & $M$ & $(s d)$ & $M$ & $(s d)$ & $M$ & $(s d)$ \\
\hline \multirow[t]{3}{*}{ Intensity ES 1} & Low SE & 53.63 & $(21.50)$ & 62.29 & $(12.60)$ & 58.18 & $(17.72)$ \\
\hline & High SE & 58.95 & (18.69) & 50.10 & $(29.28)$ & 54.41 & $(24.78)$ \\
\hline & Total & 56.28 & (20.05) & 56.34 & (22.90) & 56.32 & $(21.44)$ \\
\hline \multirow[t]{3}{*}{ Intensity ES 2} & Low SE & 51.58 & (23.72) & 52.62 & $(17.20)$ & 52.13 & (20.29) \\
\hline & High SE & 46.32 & (21.98) & 35.65 & (31.76) & 40.85 & $(27.61)$ \\
\hline & Total & 48.95 & (22.71) & 44.34 & (26.47) & 46.56 & (24.69) \\
\hline Unpleasantness & Low SE & 63.21 & (23.35) & 66.38 & (15.47) & 64.88 & $(19.42)$ \\
\hline \multirow[t]{2}{*}{ ES 1} & High SE & 64.74 & (24.72) & 66.60 & (28.03) & 65.69 & (26.14) \\
\hline & Total & 63.97 & (23.73) & 66.49 & $(22.20)$ & 65.28 & $(22.84)$ \\
\hline Unpleasantness & Low SE & 56.42 & (24.65) & 55.62 & (18.41) & 56.00 & $(21.32)$ \\
\hline \multirow[t]{2}{*}{ ES 2} & High SE & 52.89 & (26.69) & 51.85 & (34.26) & 52.36 & $(30.40)$ \\
\hline & Total & 54.66 & (25.40) & 53.78 & (27.03) & 54.20 & (26.09) \\
\hline
\end{tabular}

Note. ES 1 = first 16 s electrical pain stimulus; ES $2=$ second 16 s electrical pain stimulus; $\mathrm{SE}=$ self-efficacy.

covariate (gender) was insignificant $\left(p>.05, \eta_{p}{ }^{2}=.01\right)$. Furthermore, a main effect of Se was found, with $F(1,73)=6.28, p<.05$, $\eta_{p}{ }^{2}=.08$. Participants in the high SE group (adjusted $M=42.58$ ) rated the second pain stimulus significantly lower than participants in the low SE group (adjusted $M=50.63$ ). The effects of perceived control $\left(p>.05, \eta_{p}{ }^{2}=.03\right)$, or perceived control $\times$ SE were not significant $\left(p>.05, \eta_{p}{ }^{2}=.007\right)$.

\subsubsection{Experienced pain unpleasantness ratings}

The ANCOVA showed a significant effect for the covariate rating 1 only with $F(1,73)=102.71, p<.001, \mathrm{ES}=.59, \eta_{p}{ }^{2}=.59$. No other significant effects (gender; SE, perceived control; perceived control $\times \mathrm{SE})$ were observed $\left(p>.05, \eta_{p}{ }^{2}<.02\right)$.

\section{Discussion}

This study examined the effects of perceived control and SE on the sensory evaluation of experimentally induced pain. It was hypothesized that having perceived control over pain would lead to low pain intensity and pain unpleasantness ratings. This beneficial influence was expected to be especially enhanced for persons who possess high SE beliefs regarding their ability to exert control over pain. Results demonstrated that participants in the high SE condition expected and evaluated the second electrical stimulation to be significantly less intense, and this was independent of the control manipulation. The predicted control by SE interaction only reached significance for the expected pain unpleasantness ratings. Nevertheless, expected and experienced pain intensity ratings consistently showed the lowest ratings in the high perceived control - high SE condition.

Before proceeding to a detailed discussion of main results, it is important to discuss possible explanations for the absence of hypothesized interaction effects between perceived control and self-efficacy. One important remark concerns the fact that the perceived control group and the neutral group may not have been distinctive enough with respect to perceived control beliefs. The perceived control manipulation check indicated that participants in both conditions believed to the same moderate extent that the biofeedback strategy would influence the pain stimulus. Although we never told the participants in the neutral group that the biofeedback procedure would affect their pain, we cannot rule out the possibility that they inferred pain-reducing characteristics to the biofeedback strategy for themselves. Such inferences might be driven by pre-existing general knowledge on the putative beneficial effects of biofeedback on health complaints that might be prevalent in this sample of predominantly mental health science 
students. Alternatively, it is possible that the cover-up story as presented to the neutral group, in which it was stated that we aimed to examine if conducting skin conductance lowering was still possible while experiencing a painful stimulus, has led some participants to infer a pain-reducing effect of the biofeedback procedure on their pain experience. This might have guided especially those in the high self-efficacy condition: these participants may have been convinced that since they were very efficacious in applying the technique, the pain stimulus would not deter them from using the technique as a means to influence pain. The manipulation check indeed indicated that the belief that the biofeedback strategy would influence pain was more determined by the self-efficacy manipulation than by the control manipulation.

Although the discussion above gives reasons to doubt the effectiveness of the perceived control manipulation, other explanations might equally account for the absence of hypothesized interaction effects or the outcome of the manipulation check. For one thing, sample size $(N=79)$ might have been insufficient to detect hypothesized interactions while preserving satisfactory statistical power. In addition, caution is warranted in interpreting the manipulation check of perceived control. This specific question asks about 'the extent to which the respondent believes that the biofeedback strategy will have an influence on the pain stimulus'. It can be argued that the presentation of this particular question to participants in the neutral group might have induced perceived control expectations on the biofeedback strategy at the moment of responding to the question. Alternatively, positive responses to this question do not necessarily imply that one is also convinced that this influence on pain will operate in his or her own specific situation.

Irrespective of the effectiveness of the perceived control manipulation, results of the present study clearly demonstrate that the combination of having at one's disposal a technique that is thought to influence pain and a high SE of applying this technique leads to a reduction in the pain intensity and pain unpleasantness that one expects as well as in the actually experienced pain intensity. A number of studies have already shown that the introduction of a pain-reducing (cognitive) strategy or technique leads to reductions in expected pain intensity (Baker \& Kirsch, 1991; Bandura, 1983; Devine \& Spanos, 1990). Moreover, it has been hypothesized that when pain expectancies are dependent upon the performance of a specific skill, they will be determined by SE beliefs for that skill (Baker \& Kirsch, 1991; Bandura, 1983). In line with this suggestion, performing the biofeedback strategy in the present study can be conceived as a skill that one has to master in order to obtain beneficial effects on the following pain experience. Taken together, the present study stresses the importance of high SE beliefs about one's ability to exert control in order to observe beneficial influences of perceived control on the perception of pain (Arnstein, 2000; Jackson et al., 2002; Rokke et al., 2004). Up to now, prior studies have demonstrated the mutually strengthening beneficial effects of perceived control and associated SE beliefs on pain measures like pain tolerance and endurance of pain (Jensen \& Karoly, 1991; Litt, 1988; Rokke et al., 2004). This study adds to these findings by demonstrating that SE beliefs about an available technique to control pain also affects the sensory experience of pain, i.e. pain intensity and pain unpleasantness.

An alternative explanation for the observed influence of high SE might be that the mere conviction of being good in something is responsible for reduced pain. At least one study has come to our attention in which beneficial effects on pain tolerance were observed in participants who had induced high SE beliefs on the performance on a task that was not specifically related to pain or its reduction (i.e. a mathematical problem solving task) (Bandura, Cioffi, Taylor, \& Brouillard, 1988). In addition, it might even be speculated that participants with high SE beliefs on the biofeedback strategy have benefited from the fact that they practiced a skill in which they were good at the same time that the pain stimulus was administered. Hence, performing the biofeedback strategy during the second pain stimulus might serve as a positive distractor from the pain, resulting in reduced experienced pain intensity. These alternative explanations are of course post-hoc explanations and need further addressing in future studies.

Some limitations and recommendations are to be taken in consideration when interpreting the current results. First, the choice for a biofeedback strategy as a control technique might have impacted the results in an undesirable way. We did choose to use a fictitious biofeedback strategy that was not based on any existing or currently practiced treatment approach. However, we cannot rule out that this strategy has raised pain-reducing expectations in participants who possess prior knowledge on the wellacknowledged benefits of biofeedback strategies in diminishing physical complaints. As already mentioned above, this would have been particularly problematic for pain ratings made by participants in the neutral control group. Second, further research should devote attention to the ecological validity and the generalizability of the current findings. Participants in this study were all healthy students, and were well aware of the fact that the pain stimulus would be administered in a controlled way for a preset number of times. Replication of the current findings in a patient population is therefore advisable, in order to examine whether the effects of manipulated SE beliefs on a control strategy has beneficial effects on the subjective perception a long-term pain experience as well.

Despite these shortcomings, the current study has demonstrated that the induction of high SE beliefs regarding a pain control method elicits anticipations of less intense and less unpleasant pain for an upcoming pain experience. The current findings are interesting in the light of treatment approaches aiming at reducing pain and disability. As such, it seems advisable to induce high SE beliefs over a possibility to exert control over the pain if one aims to achieve reductions in pain and disability. These high SE beliefs might for example be induced by means of providing positive feedback and motivational support to the attempts that patients undertake in managing their pain. Given the fact that the perceived control manipulation was not as been successful as we intended in creating distinctive groups with and without perceived control beliefs, it remains to be established whether the effect of SE alone or the combination of SE and perceived control is specifically responsible for observed reductions in both expected and experienced pain.

\section{Acknowledgments}

The authors would like to thank Prof. Dr. Johan Vlaeyen for his thoughtful comments on an earlier draft of this manuscript. Furthermore, the authors are grateful to Nathalie van Aken for her help with the recruitment of participants and data collection, and to Theo van Aerts and Charlie Bonnemayer for programming and implementing the fictitious skin conductance program and the electrical stimulator. This research was supported by a grant from the Netherlands organisation for Scientific Research (NWO) with grant no. 015-001-050.

\section{References}

Arnstein, P. (2000). The mediation of disability by self efficacy in different samples of chronic pain patients. Disability and Rehabilitation: An International Multidisciplinary Journal, 22, 794-801.

Arntz, A., \& Schmidt, J. M. (1989). Perceived control and the experience of pain. In A. Steptoe, \& A. Appels (Eds.), Stress, personal control, and health (pp. 131-162). Chichester: Wiley. 
Baker, S. L., \& Kirsch, I. (1991). Cognitive mediators of pain perception and tolerance. Journal of Personality and Social Psychology, 61, 504-510.

Bandura, A. (1977). Self-efficacy: toward a unifying theory of behavior change. Psychological Review, 84, 191-215.

Bandura, A. (1983). Self-efficacy determinants of anticipated fears and calamities. Journal of Personality and Social Psychology, 45, 464-469.

Bandura, A., Cioffi, D., Taylor, C. B., \& Brouillard, M. E. (1988). Perceived self-efficacy in coping with cognitive stressors and opioid activation. Journal of Personality and Social Psychology, 55, 479-488.

Denison, E., Asenlof, P., \& Lindberg, P. (2004). Self-efficacy, fear avoidance, and pain intensity as predictors of disability in subacute and chronic musculoskeletal pain patients in primary health care. Pain, 111, 245-252.

Devine, D. P., \& Spanos, N. P. (1990). Effectiveness of maximally different cognitive strategies and expectancy in attenuation of reported pain. Journal of Personality and Social Psychology, 58, 672-678.

Feldner, M. T., \& Hekmat, H. (2001). Perceived control over anxiety-related events as a predictor of pain behaviors in a cold pressor task. Journal of Behaviour Therapy and Experimental Psychiatry, 32, 191-202.

Jackson, T., Iezzi, T., Gunderson, J., Nagasaka, T., \& Fritch, A. (2002). Gender differences in pain perception: the mediating role of self-efficacy beliefs. Sex Roles, 47 561-568.

Janssen, S. A., Spinhoven, P., \& Arntz, A. (2004). The effects of failing to control pain: an experimental investigation. Pain, 107, 227-233.
Jensen, M. P., \& Karoly, P. (1991). Control beliefs, coping efforts, and adjustment to chronic pain. Journal of Consulting and Clinical Psychology, 59, 431-438.

Litt, M. D. (1988). Self-efficacy and perceived control: cognitive mediators of pain tolerance. Journal of Personality and Social Psychology, 54, 149-160.

Pellino, T. A., \& Ward, S. E. (1998). Perceived control mediates the relationship between pain severity and patient satisfaction. Journal of Pain and Symptom Management, 15, 110-116.

Peters, M. L., Vlaeyen, J. W. S., \& Kunnen, A. M. W. (2002). Is pain-related fear a predictor of somatosensory hypervigilance in chronic low back pain patients? Behaviour Research and Therapy, 40, 85-103.

Roelofs, J., Peters, M. L., Deutz, J., Spijker, C., \& Vlaeyen, J. W. S. (2005). The fear of Pain Questionnaire (FPQ): further psychometric examination in a non-clinical sample. Pain, 116, 339-346.

Rokke, P. D., Fleming Ficek, S., Siemens, N. M., \& Hegstad, H. J. (2004). Self-efficacy and choice of coping strategies for tolerating acute pain. Journal of Behavioral Medicine, 27, 343-360.

Tan, G., Jensen, M. P., Robinson-Whelen, S., Thornby, J. I., \& Monga, T. (2002). Measuring control appraisals in chronic pain. The Journal of Pain, 3, 385-393.

Thompson, S. C. (1981). Will it hurt if I can control it? A complex answer to a simple question. Psychological Bulletin, 90, 89-101.

Williams, S. L., \& Kinney, P. J. (1991). Performance and nonperformance strategies for coping with acute pain: the role of perceived self-efficacy, expected outcomes, and attention. Cognitive Therapy and Research, 15, 1-19. 